\title{
Ultraschall DLT 2014 in Innsbruck
}

Eine Anmeldung zum Ultraschall 2014 ist ab sofort möglich und wir bitten Sie aus organisatorischen Gründen sich möglichst bald für den Kongress zu registrieren.

Alle Infos zur Anmeldung und aktuelle Informationen finden Sie auf der KongressHomepage.

- www.ultraschall2014.at

\section{Reichen Sie jetzt Ihren Vortrag ein}

Das Tagungspräsidium lädt Sie herzlich ein, wissenschaftliche Beiträge zur Präsentation einzureichen.

Das Ende der Einreichfrist ist der 26. Mai 2014 ! 